\title{
CONECTARSE CON DIOS EN LA FRONTERA. IMPRESOS CATÓLICOS Y SOCIEDAD: LA EXPERIENCIA DEL MAGDALENA DURANTE LOS GOBIERNOS LIBERALES RADICALES DEL SIGLO XIX*
}

\author{
Adriana Santos
}

\section{Resumen:}

El texto da cuenta del papel asignado a los impresos católicos por parte de la jerarquía eclesiástica en el Magdalena durante la segunda mitad del siglo XIX; en medio de un contexto político adverso a sus intereses y marcado por el intento de construcción de un orden social liberal. Se propone que el uso de periódicos, cartillas, folletos y hojas sueltas por parte del clero católico fortaleció los vínculos entre éstos y la feligresía, aumentando su presencia en las esferas política y social. Luego dichos impresos tuvieron un rol determinante que sobrepasó su uso como instrumento de guerra. En su lugar se constituyeron en una de las formas de participación política, se convirtieron en un espacio de discusión ideológica, fortalecieron la presencia de la iglesia en la sociedad y promovieron distintas iniciativas que redundaron en una mayor consolidación de la institución eclesiástica. A través de éstos se difundieron ideas, se enfrentaron a los gobiernos radicales pero también se pidieron más sacerdotes, más parroquias, más presencia en el manejo de la educación, mejores templos y una mejor atención pastoral. Por tanto, la iglesia católica hizo suyas formas de publicidad modernas con la subsecuente introducción de ésta en la sociedad civil.

Palabras clave: Impresos católicos, Estado Soberano del Magdalena, jerarquía eclesiástica, orden social liberal.

\begin{abstract}
The text gives account of the role assigned to printed by the Catholic hierarchy on the Magdalena during the second half of the nineteenth century in the midst of a political context adverse to their interests and marked by the attempt to build a liberal social order. It is proposed that the use of newspapers, booklets, brochures and flyers by the Catholic clergy strengthened the links between them and the congregation, increasing its presence in the political and social. Then these forms had a decisive role surpassed by its use as an instrument of war. Instead they formed one of the forms of political participation, space became an ideological discussion strengthened the presence of the church in society and promoted various initiatives that resulted in further consolidation of the ecclesiastical institution. Through spread these ideas, governments faced radical but also called for more priests and more parishes, more presence in the management of

\footnotetext{
* Artículo de investigación tipo 2: de reflexión según clasificación de Colciencias

* Magíster en Historia, Profesora del Departamento de Historia de la Universidad del Valle - Colombia. Miembro del grupo Región reconocido por Colciencias en categoría A1. E-mail: aysandel@ univalle.edu.co.
} 
education, better churches and better pastoral care. Therefore, the Catholic Church endorsed modern forms of advertising with the subsequent introduction of it in civil society.

Key words: Printed catholics, Sovereign State of Magdalena, ecclesiastical hierarchy, liberal social order.

\section{Una breve presentación}

La iglesia católica, entendida como un actor y encarnada por su jerarquía y clero, tuvo un accionar fundamental en diversos acontecimientos y procesos que acaecieron en el Estado Soberano del Magdalena. Durante este período, y debiendo enfrentar la propuesta de los gobiernos liberales radicales de construcción de un orden social liberal así como la secularización, su comportamiento incluyó actitudes de oposición, beligerancia, negociación, transformación y acoplamiento a las situaciones derivadas de los procesos antes mencionados. Para ello recurrió a instrumentos que no sólo le permitieron sobrevivir sino fortalecerse institucional y socialmente. Esto ocurrió con los impresos. De ahí que a continuación se muestre de qué manera uno de los componentes considerados como parte de lo moderno fue aceptado, apropiado y utilizado por el Obispo José Romero, cabeza de la iglesia en esta subregión de la costa atlántica colombiana, en favor de los intereses eclesiales. Para ello se examinarán los diversos propósitos y usos dados a los escritos, las diferentes formas y tipos de impresos y por último, las implicaciones que los dos anteriores tuvieron para la institución eclesiástica y la sociedad en general. Sobre estos asuntos se escribirá a continuación.

\section{Más allá de un instrumento de guerra y a propósito de la diversidad de impresos}

Las autoridades eclesiásticas del Magdalena hicieron de lo escrito y de las publicaciones un mecanismo efectivo al momento de optimizar su participación en el acontecer político y en la vida social ${ }^{1}$. En la primera de las esferas, la producción y circulación de textos escritos buscó y logró -con diferentes niveles de éxito en los resultados- el enfrentamiento del adversario político tanto en términos discursivos como en la práctica. A través de éstos se discutieron las medidas tomadas por los gobiernos liberales, se esbozaron argumentos que sustentaban las posiciones de la iglesia, se construyeron imágenes de los radicales y sus proyectos e incluso, se generaron hechos concretos por parte de los destinatarios e interlocutores de dichos impresos. Se trataba, entonces, de un entramado complejo en el cual la utilización de lo escrito como un instrumento de lucha

\footnotetext{
${ }^{1}$ Dentro de la bibliografía que ha tratado las relaciones existentes entre iglesia y política en el contexto latinoamericano se puede mencionar Cárdenas Ayala, E. (2007). Connaughton, B. (2007). Serrano, S. (2008). Ayrolo, V. (2007). En el caso de Colombia ver Londoño Vega, P. (2004). Ortiz, L. J. (2004; 2005; 2010). Arango, G. M. (1993). De la misma autora junto a Arboleda Mora, C. (2005). Cortés, J. D. (1998; 1997). Arias, R. (2003).
} 
política a partir de la definición del contrario como enemigo -mediante el uso del lenguaje- fue tan sólo uno de los elementos constitutivos de los textos; pero de esto se hablará más adelante. Por ahora la mirada se concentrará en los tres elementos arriba mencionados -discusión de las reformas, defensa de las posiciones del clero católico y el llamado a las acciones- que definieron el carácter de los escritos producidos ${ }^{2}$.

Las críticas a las reformas liberales fue uno de los objetivos trazados y usos dados por parte del Obispo Romero a los impresos que promovió, específicamente a través de constantes comunicaciones -una de las formas de impresos- que se hicieron llegar a las instancias legislativas. En ellas el Obispo debatía las normativas sobre desamortización de bienes de manos muertas, administración de los cementerios, matrimonio civil, libertad de cultos, libertad de imprenta, libertad de enseñanza, derechos civiles, reforma educativa y participación del clero en las elecciones ${ }^{3}$. Además, en esos mismos documentos, exponía las posibles soluciones a sus inconformidades, en donde por supuesto la institución eclesiástica se presentaba como agente de las medidas ya modificadas al tiempo que conservaba algunos de los privilegios que hasta ese momento había tenido.

De otra parte el debate de las normas también se dio en misivas abiertas que se hicieron circular y cuyos lectores, dado su contenido, debían ser clérigos y funcionarios del gobierno. En esta otra forma de comunicación se acudió al cuestionamiento teórico de las normativas, se arguyó el incumplimiento de los mismos principios liberales que decían defender las nuevas disposiciones al tiempo que se llamó a la movilización y la acción. Así ocurrió en el caso de la ley de desamortización de bienes de manos muertas y la participación electoral del clero.

En el caso de las medidas tomadas frente a las propiedades de la iglesia, el Obispo Romero escribió mensajes expeditos en donde se demostraba como dicho decreto atentaba contra uno de los pilares elementales defendidos por los radicales: la propiedad privada. A la vez se ordenaba a los sacerdotes no entregar ningún bien a las autoridades del Estado del Magdalena so pena de ser excomulgados y expulsados de la iglesia; por lo que se hacía un llamado explícito a los clérigos frente a los comportamientos que se debieran acometer, o como ya se dijo antes, se trató de estimular y apoyar acciones por parte de ciertos sectores e individuos ${ }^{4}$.

\footnotetext{
${ }^{2}$ En la perspectiva de la lectura crítica de algunos de los argumentos que se han dado por sentados a la hora de explicar la política en América Latina cabe mencionar la compilación hecha por Paula Alonso sobre construcciones impresas. En su conjunto, los artículos presentan el periodismo y la prensa como una de las múltiples formas de participación política; formas que por lo demás no sólo eran "un arenero de sangre" sino implicaba la discusión pública, la constitución de una opinión pública, el impulso de valores, la modernización de la sociedad y la construcción de imágenes sobre y desde la sociedad. En pocas palabras, se propone entender la prensa como escritos producidos en un entorno específico y como componentes clave de una situación dada (Alonso, P., 2003).

${ }^{3}$ Ejemplo de esto es el documento escrito por José Romero en 1864 dirigido al Congreso (Romero, J., 1864).

${ }^{4}$ El mismo Obispo Romero escribía “... i declaro ahora i para entonces, que la iglesia que gobierno
} 
De otra parte, se defendió el derecho al voto del clero y su participación directa en política a la luz de la separación del Estado con la iglesia (A.E.M., Tomo 102, folio 92 a 127, Enero 24 de 1878). También se escribió sobre derechos inalienables en la Circular No. 40, Del obispo a los curas (A.E.M., Tomo 108, folio 00069, Abril 17 1875). Al quedar por fuera de la esfera estatal, no se le podía exigir a la clerecía que no opinara en política y no ejerciera el derecho al sufragio. Por el contrario, los miembros del clero católico debían ser reconocidos como ciudadanos y por tanto debían gozar de todos sus derechos; razón por la cual el Obispo mostraba su extrañeza frente a lo que en su opinión sería la única constitución del mundo que negaba el sufragio a los clérigos (A.E.M., Tomo 114, folio $0005 r$ a $0006 r$, febrero 15 de 1880). De esta manera se reclamó el ser parte de la sociedad civil. Pero también se aducía el hecho de que los católicos constituían la mayoría de la población votante y por tanto esta situación debía tener expresión en los resultados electorales. De lo contrario habría una contradicción entre mayoría y representación; pero también entre mayoría y soberanía. A partir de esta última noción se aclaraba en los escritos que "...el pueblo tiene derecho a pedir, y ha pedido, y viene pidiendo, y pide las verdaderas luces del saber humano" (A.E.M., Tomo 114, folio 0009, s.f.). Derecho que debía respetarse mucho más si se tenía en cuenta que era ese mismo pueblo el que elegía a los gobernantes y además asumía la financiación de los gastos generados por sus servicios.

En otros escritos, además, se defendieron sus derechos a partir de las nociones de libertad de expresión, libertad de imprenta y libertad de prensa; siendo precisamente éstas últimas las bases en las cuales apoyaron todas sus iniciativas en relación con la divulgación de sus ideas a través de las variadas formas de publicaciones 5 . De ahí que tanto en las cartas escritas al congreso, en las hojas sueltas como en los periódicos se pusiera de presente su derecho legítimo a difundir públicamente sus ideas y las directrices trazadas por Roma, las autoridades eclesiásticas y la dirigencia conservadora. Las denuncias sobre la violación de las libertades y persecución de la iglesia por parte de "un tribunal inapelable de censura a la palabra y a los escritos de los mismos ministros" se mostraron como una contradicción de esa "república democrática de tantas libertades" (A.E.M., Tomo 105, folio 99, s.f.).

Pero también fue en este contexto en el cual se hicieron esfuerzos por crear sus propios medios de expresión: ante los embates de la "prensa atea" fue urgente la creación de "prensa católica", con lo cual se abrieron paso hacia la utilización de los periódicos. De ahí la iniciativa de Romero por fundar un órgano oficial de la diócesis, hacia el año 1876, llamado Repertorio Eclesiástico y cuyo objetivo fue

\footnotetext{
transitoriamente, no se desprende, cede, traspasa, ni renuncia de todos i cada uno de sus bienes i rentas, otros i acciones que hará valer contra estraño poseedor". Archivo Eclesiástico del Magdalena (en adelante A.E.M), Tomo 74. Interna 22. Junio 11 de 1862.

${ }^{5}$ Sobre el uso de argumentos liberales por parte de la iglesia para defenderse de los ataques de los mismos liberales en Argentina y Chile ver Serrano, S. (2000) y Zanatta, L. (2000).
} 
neutralizar los "altares a la dios Razón" (A.E.M., Tomo 104, folio 198, Septiembre de 1876) al tiempo que llevaría mensajes a los feligreses sobre la situación del catolicismo en esos arduos momentos.

Según el jerarca, las condiciones por las que se atravesaba bajo el gobierno radical y en pleno auge del protestantismo obligaban a "popularizar" la prédica del evangelio mediante mecanismos eficaces a la hora de llevar el conocimiento de Dios a todos los creyentes (A.E.M., Tomo 104, folios 168 a 170, Noviembre 12 de 1876). En esta lógica, la prensa satisfacía la necesidad de comunicación de los principios católicos y de salvaguardia de sus privilegios. Así lo entendieron también varios párrocos locales. Entre ellos Manuel J. Manjarrés, quien afirmó que "si los escritores heterodoxos difunden sus periódicos en las ciudades, pueblos i aldeas", era una obligación de los buenos católicos hacerlo "con los periódicos que se han encargado de la noble empresa de rechazar y evidenciar esas producciones asquerosas contra la santa relijión" (A.E.M., Tomo 104, folios 168 a 170, Noviembre 12 de 1876). Por tanto, poco a poco y en medio de dificultades económicas se impulsó la existencia de publicaciones religiosas y católicas que incluyeron los ya citados periódicos además de otros escritos como cuadernillos y folletos ${ }^{6}$. Situación que resulta interesante puesto que se está frente a una institución "tradicional" defendiendo sus prerrogativas mediante un instrumento "moderno" y con los mismos argumentos de aquellos a quienes cuestionaban, esto es, los principios liberales en torno a la libertad de imprenta, la libertad individual, la libertad de opinión y la libertad religiosa. Por tanto, en la crítica al proyecto de un orden social liberal, miembros regulares de la iglesia fueron incorporando principios liberales en su discurso y en su práctica; al mismo tiempo que hicieron uso de las formas de la política moderna.

Del mismo modo en el ámbito de las comunicaciones dirigidas a sectores específicos se produjeron cartas y cuadernillos en donde se cuestionó una de las leyes más importantes dentro del conjunto normativo de los gobiernos radicales: el decreto orgánico de instrucción pública que declaró la educación laica y bajo control del Estado. Directores de escuela, padres de familia y nuevamente curas recibieron textos en los cuales se pusieron en evidencia las críticas de Romero frente al proyecto educativo radical, se expusieron las contrapropuestas hechas por la jerarquía eclesiástica y algunos miembros del partido conservador, se desarrolló la campaña de descrédito del sistema de instrucción y por último, se conminó al acatamiento de las orientaciones dadas por el Obispo en cuanto a las actuaciones que como católicos comprometidos debían acometer ${ }^{7}$. Así que en esta ocasión, confluyeron los diferentes usos de los escritos enunciados en párrafos anteriores.

\footnotetext{
${ }^{6}$ Estos cuadernillos también fueron una salida para superar la crisis económica de los periódicos puesto que su publicación era más barata. Esto se abordará más adelante.

${ }^{7}$ Cabe aclarar que no todo fueron críticas y cuestionamientos. Romero compartía el énfasis del gobierno liberal en la apertura de escuelas y en su masificación, pero criticaba los contenidos impartidos en dichas instituciones así como el evidente hecho de la pérdida de control de la iglesia sobre la administración de los establecimientos educativos.
} 
Los textos contenían respuestas a las medidas centrales de los liberales en el plano educativo: el establecimiento de escuelas, la formación de profesores, los métodos de enseñanza y la selección, impresión y distribución de textos escolares, entre otros. Cada una de ellas fue objeto de varias estrategias. Una, consistió en la discusión en el plano de lo discursivo/argumentativo incluyendo reivindicaciones de las libertades públicas; específicamente la libertad de enseñanza y la libertad religiosa. Otra se basó en la exposición de reflexiones sobre la importancia de la instrucción religiosa, la presentación de alternativas como la enseñanza del catolicismo y la apertura de instituciones educativas católicas; elementos que implicaban la conformación de instituciones privadas orientadas por el clero católico.

Y es aquí en donde aparecieron el llamado a las acciones pero también la ejecución de las mismas. Se escribió a los párrocos locales y padres de familia convocándolos a la creación y puesta en marcha de las Confraternidades de la Enseñanza de la Doctrina Cristiana cuyo propósito fue garantizar la difusión de los principios del catolicismo entre los habitantes y especialmente los niños de las parroquias (A.E.M., Tomo 105, folio 00032, Enero 5 de 1874). Al mismo tiempo se invitó, y de hecho se dio, la apertura de escuelas primarias coordinadas por párrocos o fieles que quisieron contribuir en la defensa del catolicismo. De tal manera, que se avanzó en el camino de la institucionalización de la iglesia y del fortalecimiento de los lazos con los miembros de las comunidades. Aparecieron círculos doctrinales (A.E.M., Tomo 90, s.f., Año de 1875) y escuelas bajo la responsabilidad de curas y vecinos, quienes asumieron su dirección, financiación y acudieron a éstas (A.E.M., Fondo José Romero, Vol. 5, folio 192, Enero 1 de 1868). De paso y como resultado de los nuevos vínculos entre los habitantes de las localidades y el obispo así como de la necesidad de comunicación entre todos estos actores, unos y otros recurrieron a la escritura. Comenzaron a circular informes sobre el funcionamiento de las recién fundadas instituciones dirigidos a Romero, hubo intercambios de hojas sueltas con denuncias a cerca de los opositores -bien fueran vecinos o funcionarios del gobierno- a los círculos y escuelas católicas, aparecieron contra respuestas a éstas últimas y se recibieron instrucciones del Obispo Romero sobre cómo continuar procediendo. En fin, en este punto los pobladores de las localidades hicieron uso de la escritura, de la lectura y generaron impresos. Lo mismo aconteció con la jerarquía católica.

A partir de lo inmediatamente anterior se puede dar un acercamiento a lo que al comienzo de este apartado se denominó como la participación de la iglesia católica en la vida social a partir de los impresos. Su publicación y circulación estrechó los vínculos entre el Obispo Romero y su feligresía al fortalecer su presencia a lo largo del territorio. A través de los escritos intentó el fortalecimiento de las parroquias, pidió donaciones, estableció misiones, realizó jornadas de ornamentos de los templos e incentivó y avanzó en la participación de los vecinos -en parroquias y pueblos- en actividades de las cofradías, círculos doctrinales, escuelas y colegios privados y otras formas asociativas. Una vez más, la iglesia se mostró moderna al responder ante la irrupción de la secularización y de las ideas liberales. La "gente" por su parte pidió más sacerdotes, más parroquias, más 
presencia en el manejo de la educación, mejores templos y una mejor atención pastoral. Aún así, de manera general, se sugiere que está población considerada como tradicional también se adaptó a los cambios de tal manera que vivió espacios tradicionales y modernos.

Ahora bien, retomando la cuestión de los usos de lo escrito en los impresos generados como reacción a la reforma educativa de 1870, faltaría por abordar la manera en que el lenguaje y las palabras fueron estrategias de la jerarquía eclesiástica para responder los embates del liberalismo. Los escritos se llenaron de definiciones cargadas de juicios de valor tendientes a identificar a los contradictores como representantes del error y enemigos del catolicismo. Las referencias al tipo de educación brindada en las escuelas fundadas por el radicalismo, los planteles de instrucción, los maestros de las escuelas oficiales y los padres que accedieron a matricular a sus hijos en dichas instituciones estuvieron cargadas de enunciaciones y disquisiciones llenas de adjetivos.

Según las circulares, folletos y cartillas, la educación derivada de la aplicación del decreto orgánico de 1870 era "materialista y atea" (A.E.M., Tomo 104, folio 105, Mayo 23 de 1876). Las instituciones educativas fueron consideradas como "fuente de corrupción y embrutecimiento" y la instrucción ofrecida en ellas enseñaba a "buscar el pasto de los goces más groseros", "la satisfacción de sus pasiones" y "...no reparan en minar el edificio por sus cimientos y debilitan el ascendiente de la religión y dan lugar a la relajación moral" (A.E.M., Tomo 109, sin folio y sin fecha). El resultado de este sistema educativo sería, según la opinión del Obispo Romero expresada en los textos que circularon, la degradación de la sociedad, el triunfo de la subversión de los jóvenes y el auge de los vicios, las bajas pasiones y las tribulaciones (A.E.M (enero 1 de 1883). Religión. La Ciencia, Santa Marta (Hoja suelta), ( $\mathrm{n}^{\circ} 1$, trim. 1), p. 2); siendo esto último la contraparte de la ausencia de la enseñanza del catolicismo.

Los responsables de impartir los conocimientos tampoco escaparon de la presión ejercida por Romero a través de la estigmatización en sus comunicaciones. En las hojas sueltas de su autoría se podía leer como se refería a los profesores como "energúmenos doctorcillos al servicio de la "ignominia del liberalismo" (A.E.M., Tomo 87, folio102, sin fecha), y responsables del envenenamiento de las juventudes. Los padres de familia, por su parte, recibieron correspondencia en la cual se advertía sobre las "tendencias corruptoras" que estaban recibiendo sus hijos al asistir a las escuelas públicas y por tanto, se les responsabilizaba de facilitar su "inmolación en las aras asquerosas del liberalismo"8.

Las anteriores expresiones confirman algo ya reconocido por la historiografía y que tiene que ver con el uso político de las publicaciones y sobre todo, con su papel en la construcción de imágenes en donde se definía a los opositores desde

\footnotetext{
${ }^{8}$ Comunicación del obispo Romero a los padres de familia mediante carta abierta (A.E.M., Tomo 103, folio 204, año de 1875).
} 
la relación amigo/enemigo. Sin embargo es necesario introducir aquí un matiz a dichas aseveraciones. En concreto en lo relacionado con el excesivo énfasis puesto en el papel del lenguaje estigmatizador a la hora de resolver los conflictos políticos entre iglesia católica y liberales radicales. Más allá y además de ser un arma de combate y desplegar las banderas de la intransigencia frente al enemigo político; lo impreso también es político en tanto que permitió la discusión ideológica de los postulados, la configuración de identidades, la formación de una opinión pública y posibilitó la actuación de ciertos sectores sociales, complejizando los procesos. Desde esos escritos se apoyaban campañas políticas, se hacían circular rumores, se pedían adhesiones, se derivaron intervenciones concretas que conllevaron una injerencia en la escena partidista más allá de la confrontación física e incluyeron una defensa y fortalecimiento de la institución eclesiástica.

Hasta aquí, y para ir sintetizando lo hasta el momento expuesto, se podría afirmar que los impresos católicos en el Magdalena de la segunda mitad del siglo XIX buscaron responder al liberalismo, ganar unidad entre los viejos y nuevos miembros de la iglesia católica, fortalecer su sentido como comunidad e institución, crear una opinión pública católica y propender por la actuación de los fieles en correspondencia con lo anterior. De ahí que los contenidos giraran en torno a mostrar las posiciones que se debieran tomar frente a sus contradictores, exponer las adhesiones a candidatos, opinar en contra de los opositores, defender y fortalecer los valores del catolicismo, hacer comentarios sobre los acontecimientos sucedidos tanto en las campañas que se defendía como a las que se hacía oposición, difundir las directrices de la jerarquía eclesiástica del país y de Roma frente a las medidas liberales y la institucionalización de la iglesia, cuestionar o afirmar las decisiones tomadas por los diferentes sectores políticos con respecto a la iglesia y la religión, y orientar las acciones de los miembros de la iglesia bien fuesen clérigos o feligreses.

De lo inmediatamente anterior se pueden hacer dos precisiones. De un lado, la separación entre lo que se ha denominado lo político y lo social para efectos de la actual exposición; no se da en la realidad pues es evidente que ninguna se constituye como entidad autónoma y separada de la otra. De hecho, al tiempo que se cuestionaba el cuerpo legislativo liberal, se compelía a los sacerdotes, vecinos, feligreses, padres de familia, profesores y pobladores en general para que no acataran las nuevas medidas; la clerecía tomaba acciones orientadas a fijar su presencia en el territorio e interactuaba junto a los fieles, quienes tomaban sus propias decisiones y asumían prácticas conforme a éstas últimas. De otro, la iglesia se mostró moderna al responder ante la irrupción de la secularización y de las ideas liberales. Lo mismo ocurrió con los pobladores.

De otra parte, para hacer efectivas las pretensiones citadas en los párrafos inmediatamente anteriores, se recurrió a cuanta forma de publicación se pudo acceder. Se intentó con la prensa, se apeló a ediciones con costos de publicación más bajos, se buscó facilitar la circulación. De ahí que la jerarquía, el clero y los feligreses produjeran, recibieran e intercambiaran periódicos, cartas abiertas, circulares, manifiestos, folletos, cartillas y hojas sueltas. 


\section{Un poco más que periódicos: otros apuntes sobre la variedad de publicaciones y el auge de lo escrito}

A propósito de la multiplicidad de impresos católicos que circularon por el espacio del Estado Soberano del Magdalena se considera pertinente puntualizar, con algunos casos concretos, aquellos intentos por consolidar las diferentes publicaciones católicas y llamando la atención sobre los progresos alcanzados frente al uso de lo escrito. La revisión de la experiencia que se tuvo con un periódico local, una cartilla y un folleto resulta útil al momento de sustentar la existencia de una gama amplia de escritos que hicieron parte del mundo de lo impreso. Más allá de los periódicos, existieron diversos medios de expresión escritos que recogieron las preocupaciones, motivaciones y esfuerzos de una también variada gama de actores. Situaciones éstas que lleva a reconocer un avance en los procesos de lectura y escritura y su apropiación por parte de franjas más amplias de población; tal y como lo indican la variedad de emisores y receptores de las comunicaciones pero también los constantes informes y registros de las actividades relacionadas con la labor de los miembros de la iglesia -libros de bautismo, matrimonio y defunción, sermones y pastorales e incluyendo correspondencia con autoridades civiles- que se encontraron en el archivo eclesiástico del Magdalena.

Las razones para que fuera posible esto incluyen el impulso dado a la instrucción primaria y los cambios generados en la opinión pública. Bien pudiera plantearse que con lo uno se mejoró el nivel de formación del clero y se amplió la posibilidad de recepción y generación de escritos en los pobladores. Con lo otro, las autoridades eclesiales reconocieron en lo escrito una herramienta capaz de asegurarles su participación en las dinámicas políticas y fortalecer su capacidad de reacción frente a las reformas. Escenarios estos que denotan las capacidades de la iglesia católica al momento de adaptarse a las nuevas condiciones generadas a partir de las reformas liberales. La institución eclesiástica poco a poco hizo suyos a lo escrito y lo impreso. Se está ante una iglesia católica que se apropió de la cultura escrita y coadyuvó a la formación del espacio público moderno, instalándose en él; con lo cual entró a hacer parte de lo moderno 9 .

Uno de los primeros intentos que se hizo en relación con hacerse partícipes del mundo de las publicaciones fue a través de los periódicos. Hacia fines de 1869 el Obispo Romero planteó la creación de La Unidad Católica con el fin de propagar la doctrina del catolicismo e invitar a la salvaguardia de la iglesia y sus compromisos sociales $^{10}$. Según el mismo Romero era urgente fundar un periódico "...que a la vez sea el órgano de los actos del episcopado de esta provincia, defienda los sagrados derechos de la iglesia católica i el depósito de su enseñanza" así como llamaba la atención sobre lo importante de garantizar su buen funcionamiento a través de "la realización del convenio celebrado en esa metrópoli entre los padres

\footnotetext{
${ }^{9}$ Al respecto ver Serrano, S. (2008). Op. Cit. También Serrano, S. \& Jaksic, I. (2000). pp. 435 - 460.

${ }^{10} \mathrm{La}$ idea del periódico propuesta por Romero, en julio de 1869, es aceptada por el arzobispo de Bogotá.
} 
del concilio..." y de "las suscripciones las cuales se estarán a cargo de los vicarios y algunos seglares" (A.E.M., Tomo 92, folio interno 13 y 13r, julio 31 de 1869). El editor fue José Antonio Acosta, se fijó una periodicidad mensual, se definió la manera en que se haría rotar entre sus lectores y se acordó como medio de financiación lo recaudado por efectos de las suscripciones hechas por fieles y párrocos. No obstante, este último aspecto fue la dificultad más fuerte tanto para la edición y vigencia de este periódico como de los demás impresos que se intentaron poner en circulación.

De ahí que el Obispo llamara la atención al clero sobre lo vital de lograr el apoyo económico al periodismo religioso. En sus propias palabras “...i así como los impíos i materialistas, los inventores de sistemas de moral, sostienen i circulan aquellas publicaciones, es preciso, es indispensable, de que a la vez el clero, i los buenos católicos; apoyen i propaguen con su influencia, con su ilustración i dinero al periodismo religioso" (A.E.M., Tomo 98, Enero 1 de 1872). Llamados de atención que poco efecto tuvieron dadas las circunstancias económicas del Magdalena. Los sacerdotes declaraban sobre su pobreza y las consecuencias de las guerras (A.E.M., Tomo 168, Noviembre 1876) al tiempo que informaban de la devolución de los ejemplares que no se habían podido entregar por falta de pago y mostraban su preocupación por los pocos números vendidos (A.E.M., Tomo 103, folio 00060, Marzo11 de 1872).

Otra experiencia, resultado de las vicisitudes financieras, fue la emprendida desde comienzos de 1872 con El tradicionista, periódico dirigido por Miguel A. Caro y publicado en Bogotá. La puesta en circulación de un impreso cuyos costos de edición no tuvieran que cubrirse localmente fue considerada como una buena opción para solventar los problemas económicos y cumplir a la vez con las obligaciones del prelado. Toda vez que sus contenidos recogían "los luminosos principios católicos" de manera acertada, Romero instó a los curas para que acogieran esta publicación "que defiende con laudable franqueza y lealtad la Doctrina Católica" (A.E.M., Tomo102, folio 46, s.f., Enero 8 de 1872). Una vez más la invitación incluyó un llamado a mantener las suscripciones, aun cuando esto implicara sacrificios económicos. Se estaba ante una "necesidad" a la que se debía responder con compromiso cristiano: la defensa de la religión (A.E.M., Tomo 103, folio 0193, Agosto 28 de 1872).

Estos inconvenientes presentados por los periódicos llevaron a que Romero y el resto del clero buscaran algunas otras alternativas para la publicación de sus ideas y planteamientos. La salida fue encontrar impresos más baratos. De ahí surgieron las cartillas, los folletos, las hojas sueltas y las cartas abiertas. Todas ellas bajo nombres distintos y énfasis diferentes en sus contenidos, eran textos cortos de una extensión máxima de tres hojas, cuya edición no comprometía una periodicidad y con una circulación abierta y pública.

La orientación de las dos primeras estuvo marcada por la alusión a reflexiones teóricas y filosóficas sobre las acciones de los gobiernos liberales. En estos textos Romero hizo despliegue de su erudición y de sus lecturas para cuestionar los 
principios en los cuales se basaban las propuestas radicales. Por ejemplo, en la cartilla titulada La verdad y Los Sofismas el obispo cuestionaba la ilustración, el racionalismo y la secularización como los dogmas errados en los cuales se sustentaba el despojo hecho a la iglesia católica. Abiertamente defendía su permanencia en la vida de toda sociedad pero sobre todo la definía como una responsabilidad de los gobiernos cuando señalaba "Para que cualquier sistema político pueda hacer feliz al pueblo debe sembrar la religión y la moral, para así cumplir con la misión confiada por el supremo legislador del universo" (A.E.M., Cartilla La verdad y los sofismas).

En un tono similar publicó otro cuadernillo en el año de 1876. En esta ocasión, Romero se refirió al carácter del modelo económico liberal, la concepción de la libertad y las implicaciones de ambas. En el texto el Obispo definió la época de ese momento como la más lamentable y triste que se hubiese registrado en "Los anales históricos" al tiempo que se preguntaba sobre la exagerada "licencia" dada a los "principios libres, las libres creencias y el libre libertinaje" y su relación con la ilustración y los filósofos defensores de la misma. Para lo cual hizo un recorrido por los planteamientos de personajes como Rousseau y Voltaire al tiempo que se ocupó de revisar los sistemas filosóficos y morales que en su opinión se ocupaban de reivindicar "las estrechas relaciones del hombre con todo cuanto le rodea" dejando por fuera el papel del "espíritu divino". Las consecuencias de todo ello también fueron expuestas por el Obispo en este escrito: “... Jamás la negación absoluta ha tenido el apogeo que hoy y jamás la libertad de pensar y obrar había alcanzado un predominio tan extenso como en el que el día posee". Por último advertía sobre algunos de los efectos que todo lo anterior tenía sobre la vivencia católica y sobre comportamientos como "la pereza para asistir a los oficios religiosos, las blasfemias, el lujo y las diversiones desmedidas" y de "encender la hoguera de ambición desmedida por el dinero". Empero, era mucho más enfático cuando criticaba, lo que en su visión era una "libertad salvaje" (A.E.M., Tomo 104, folios 170, Noviembre 12 de 1876).

Por último se puede referenciar el contenido de cuatro folletos publicados durante la segunda mitad de la década del setenta. En esta ocasión los escritos se concentraron, más bien, en presentar críticas a cada una de las medidas y decretos adoptados por los gobiernos radicales, a brindar orientaciones sobre las formas de actuación y acciones a emprender por los diferentes actores e incluso, la exposición de puntos de acuerdo con los gobiernos y funcionarios vigentes. Aun cuando cabe aclarar que esto último ha sido relegado por la mirada de los historiadores quienes han privilegiado los primeros elementos $y$ por lo que se ha contribuido a la construcción de una imagen en donde el conflicto y la agresión son protagonistas.

Se trata de escritos de dos y tres hojas de extensión cuyo asunto tratado fue el tema educativo y cuyo propósito fue la divulgación de la posición de la iglesia católica frente a algunos aspectos de la reforma educativa liderada por los gobiernos liberales radicales, bien se tratasen de aspectos discursivos o 
prácticos ${ }^{11}$. Dada la centralidad de la instrucción primaria, el Obispo Romero se esforzó por publicitar su postura frente a asuntos como la naturaleza de la educación que se debía impartir, la enseñanza del catolicismo, las asignaturas de los planes de estudio, el contenido de las asignaturas, la formación y el papel de los maestros, las misiones pedagógicas extranjeras y el papel de los padres de familia en el proceso de instrucción y formación de sus hijos. Para ello priorizó como receptores principales de estos escritos a quienes tenían la responsabilidad de enseñar en las instituciones educativas y quienes debían asegurar la asistencia de los niños a la escuela. Especialmente a ellos se dirigió.

\section{Hacia el asentamiento en la sociedad civil: consideraciones finales}

En este contexto es factible presentar algunos apuntes en relación con los alcances que tuvo el uso de los impresos católicos para la iglesia y para toda la sociedad. En términos generales hubo una apropiación de elementos modernos por parte de la jerarquía eclesiástica, curas y fieles expresada en diferentes eventos como las formas de publicidad adoptadas, la formación de una opinión pública católica y los cambios en las formas asociativas. Muchos -aunque unos más que otros- acudieron asiduamente al uso de los impresos católicos, expresaron e hicieron públicas sus posturas frente a los acontecimientos políticos y frente a hechos cotidianos de las localidades -que bien podían ir desde el desempeño de los funcionarios civiles y eclesiales hasta la resolución de conflictos- y por último, se congregaron en asociaciones que poco a poco fueron abandonando el carácter tradicional y adoptando en su lugar, criterios de funcionamiento modernos.

De un lado se buscó la manera en que el catolicismo lograra imponerse o por lo menos sobrevivir al liberalismo, darle unidad a la visión de los párrocos frente a los temas de la iglesia y sus relaciones con el Estado y llamar a la actuación a sus fieles. Por ende, se buscaba contrarrestar los efectos de la prensa liberal al mismo tiempo que se buscaba la creación de una opinión pública que se definiera como católica.

De otra parte, contrariando la idea del poco uso de lo escrito por parte de los pobladores del Magdalena hubo mayor producción, circulación y utilización de lo que comúnmente se ha creído. Las comunidades escriben solicitando el traslado o permanencia del cura, se publican las listas de los contribuyentes a la iglesia, se pide la colaboración económica para crear y mantener los periódicos locales o para asegurar la circulación de los periódicos regionales y nacionales. Influencia que ha sido "olvidada" debido a la correlación que se establece entre cultura escrita, formación del espacio público moderno y proceso de secularización; pero además, debido a la concepción de la iglesia como una institución del antiguo régimen y cuya capacidad de cambio se niega.

\footnotetext{
${ }^{11}$ La reforma educativa conocida como el Decreto Orgánico de 1870 fue uno de los aspectos que causó mayor debate entre los radicales y la iglesia católica no obstante existía consenso sobre su pertinencia para que el pueblo alcanzara el progreso.
} 
Con todo, la iglesia católica en el Magdalena terminó fortaleciendo y legitimando el orden liberal por cuanto ella misma puso en evidencia que los instrumentos y derechos ofrecidos en este marco se podían utilizar, aún fuera por sus críticos. Al mismo tiempo, la iglesia misma se consolidó a pesar de no haber impedido su separación con el Estado; logrando posicionarse en la dimensión de lo público, instalándose en la sociedad civil y modernizando sus estructuras institucionales. En esta dinámica participaron todos sus miembros, incluso sectores marginados del mundo político o ausentes de la vida pública hasta ese momento.

Luego es necesario revaluar la idea generalizada de la Costa Caribe como una región en donde la iglesia tuvo poca o ninguna presencia. Por el contrario, ésta se fortaleció institucionalmente durante este período debido a los esfuerzos realizados por la jerarquía eclesiástica, el clero y los fieles en torno al fomento de la producción y utilización de impresos así como a la creación de parroquias, cofradías y asociaciones y el aumento de la sacralización ${ }^{12}$. Pero también debido a su capacidad de adaptación a las particularidades locales así como a los cambios y nuevas medidas generados en pos de la construcción de un orden social liberal.

Es necesario reconocer a la Iglesia como una institución capaz de adaptarse a las exigencias de los diferentes órdenes sociales; llegando incluso a la incorporación de principios liberales en su discurso y en su práctica; al mismo tiempo que hizo uso de las formas de la política moderna. Así, los estudios sobre la institución eclesiástica dejan de otorgarle a dicha institución un carácter tradicional, y comienzan a verla como una institución que hizo suyas prácticas modernas: asociaciones, prensa y partidos. El análisis de los impresos católicos supera el nivel ideológico para concentrarse en su rol como vinculante entre los miembros de la iglesia y la sociedad, pone en escena a los actores -receptores y productores de las diversas formas impresas sean estos pobladores de las localidades o capitales, párrocos, autoridades eclesiásticas o políticos- y abandona antípodas como tradición/modernidad.

\section{REFERENCIAS BIBLIOGRÁFICAS}

\section{Fuentes documentales}

Archivo Eclesiástico del Magdalena, Fondo José Romero, Santa Marta, 1850 1886.

\footnotetext{
${ }^{12}$ La comprensión de esta situación exige el distanciamiento de aquellos presupuestos que esperan encontrar en el siglo XIX una institución eclesiástica consolidada y fuerte que se supone heredada de la colonia y cuya existencia se reconoce para otras regiones del país. No obstante, aquí se propone una iglesia en construcción a lo largo del siglo mencionado con capacidades de adaptación y respuesta a los diversos contextos locales. De ahí las características particulares del catolicismo de esta región y de sus instituciones.
} 


\section{Libros y artículos}

Alarcón, L., Conde, J. y Santos, A. (2002). Educación y cultura en el Estado Soberano del Magdalena (1857 - 1886). Colombia: Fondo de Publicaciones Universidad del Atlántico.

Alonso, P. (Comp.) (2003). Construcciones impresas. Panfletos, diarios y revistas en la formación de los estados nacionales en América latina, 1820-1920. Buenos Aires: Fondo de Cultura Económica.

Arango, G. M. (1993). La mentalidad religiosa en Antioquia. Prácticas y discursos. 1828- 1885. Medellín: Universidad Nacional.

\& Arboleda Mora, C. (2005). "La Constitución de Rionegro y el Syllabus como dos símbolos de nación y dos banderas de guerra". En Grupo de Investigación Religión, Cultura y Sociedad. Ganarse el cielo defendiendo la religión. Guerras civiles en Colombia. 1840 - 1902. Medellín: Universidad Nacional de Colombia.

Arias, R. (2003). El Episcopado colombiano. Intransigencia y laicidad (1850 2000). Bogotá: Ceso - Ediciones Uniandes - ICANH.

Ayrolo, V. (2007). Funcionarios de dios y de la república: clero y política en la experiencia de las autonomías provinciales. Buenos Aires: Biblos

Cárdenas Ayala, E. (2007). "Hacia una historia comparada de la secularización en América Latina”. En Palacios, G. (Coord.), Ensayos sobre la nueva historia política de América Latina, siglo XIX (pp. 197-211). México: El Colegio de México, Centro de Estudios Históricos.

Connaughton, B. (2007). "La nueva historia política y la religiosidad: ¿un anacronismo en la transición?" En Palacios, G. (Coord.), Ensayos sobre la nueva historia política de América Latina, siglo XIX. México: El Colegio de México, Centro de Estudios Históricos.

Cortés, J. D. (1998). Curas y Políticos. Mentalidad religiosa e intransigencia de la diócesis de Tunja. Ministerio de Cultura: Bogotá.

. (1997). Regeneración, Intransigencia y Régimen de Cristiandad. Historia Crítica, oㅜ 15, 3-12.

Londoño Vega, P. (2004). Religión, sociedad y cultura en Colombia. Medellín y Antioquia 1850-1930. México: Fondo de Cultura Económica.

Ortiz, L. J. (2004). Fusiles y plegarias: guerra de guerrillas en Cundinamarca, Boyacá y Santander, 1876-1877. Medellín: Universidad Nacional de Colombia. 
. (2010). Obispos, clérigos y fieles en pie de guerra. Antioquia, 18701880. Medellín: Editorial Universidad de Antioquia.

. (2005). Guerras civiles e Iglesia Católica en Colombia en la segunda mitad del siglo XIX. En Grupo de Investigación Religión, Cultura y Sociedad. Ganarse el cielo defendiendo la religión. Guerras civiles en Colombia. 1840 1902. Medellín: Universidad Nacional de Colombia.

Serrano, S. (2008). ¿Qué hacer con Dios en la República? Política y secularización en Chile (1845-1885). Santiago: Fondo de Cultura Económica.

, S. (2000). "La estrategia conservadora y la consolidación del orden liberal en Chile 1853 - 1890". En Carmagnani, M. (Coord.). Constitucionalismo y orden liberal en América Latina, 1850 - 1920 (pp. 121- 148). Torino: Otto editore.

, S. \& Jaksic, I (2000). "El poder de las palabras: La iglesia y el estado Liberal ante la difusión de la escritura en el Chile del siglo XIX". Historia, Instituto de Historia, Pontificia Universidad Católica de Chile, Vol. 33, pp. 435 460 .

Zanatta, L. (2000). "De la libertad de 'culto posible' a la libertad de culto 'verdadera'. El catolicismo en la formación del mito nacional argentino, 1880 1910". En Carmagnani, M. (Coord.). Constitucionalismo y orden liberal en América Latina, 1850 - 1920 (pp. 155 - 199). Torino: Otto editore.

Recibido: Octubre 7 de 2011

Aprobado: Noviembre 29 de 2011 